\title{
The temporal interpretation of West Flemish non-inverted $\mathrm{V}^{1}$
}

\author{
Liliane Haegeman \\ DiaLing: Ghent University
}

\begin{abstract}
This chapter focuses on Dutch and the West Flemish dialect. It compares the interpretation of the initial temporal adjuncts in a regular V2 pattern, in which the finite verb has inverted with the subject, and in the West Flemish V3 pattern in which an adjunct precedes a non-inverted V2 pattern. An interpretive difference emerges in the periphrastic tenses: while in the regular V2 pattern, an initial time adjunct modifies either the Reference Time or the Event Time of the associated clause, in the non-inverted V3 pattern, the initial temporal clause can only modify the matrix Reference Time. This restriction is shown to follow from the analysis elaborated in Haegeman \& Greco $(2018 \mathrm{a}, \mathrm{b})$ combined with a split Tense proposal in which Reference time and Event time are located on distinct functional heads.
\end{abstract}

\section{Introduction}

This chapter examines the interpretation of the initial temporal clauses in the West Flemish (from now on abbreviated as WF) examples in (1). (1a)

1 I dedicate this paper to Sten Vikner. Sten was my very first collaborator at the English department in the University of Geneva and though the function was labelled 'assistant', this was not at all a label fit to characterize our relationship. Sten was there from the start, also - and especially - when times were rough, and his role in building the Linguistics programme was hugely important. But not just that: Sten's research is exemplary and he keeps being an inspiration, as this paper will hopefully show. And finally, he was and remains a friend, 'in good times and in bad times'. To Sten, with fond memories of 'la neige du siècle'.

Ken Ramshøj Christensen, Henrik Jørgensen \& Johanna L. Wood (eds.). 2019.

The Sign of the V-Papers in Honour of Sten Vikner. Dept. of English, School of Communication \& Culture, Aarhus University, pp. 185-203, doi:10.7146/aul.348.95. (C) The author(s). 
illustrates a root $\mathrm{V} 2$ clause with an initial temporal clause oan-k toekwamen ('when I arrived') and the finite auxiliary was ('was') to the immediate left of the subject den eletriek ('the power'); the equivalent of (1a) is licit in Standard Dutch (from now on StD). (1b) illustrates a deviation from V2 in which the finite auxiliary is preceded by two constituents: the temporal clause and the subject. (1b) is acceptable in WF (Haegeman \& Greco $2018 \mathrm{a}, \mathrm{b})$; its analogue is unacceptable in StD.

\section{(1) a. Standard Dutch}

Oan-k toekwamen was den eletriek utgevallen. when-I arrived was the electricity out.fallen

\section{b. West Flemish}

Oan-k toekwamen, den eletriek was utgevallen. when-I arrived the electricity was out.fallen 'When I arrived, there had been a power failure.'

There are interpretive differences between the examples in terms of the scope of the adverbial clause. (1a) is ambiguous: following a Reichenbach style approach (Hornstein 1993; but see Vikner 1985; Cinque 1999, a.o.), the adjunct oan-k toekwamen ('when I arrived') has two construals. In one construal, the adjunct specifies the Reference Time of the clause it modifies, meaning that at the moment when I arrived the power was down already, i.e. the power cut precedes my arrival. In a second construal, the adjunct specifies the Event Time, meaning that the power cut takes place upon my arrival. WF (1b) with non-inverted V3 only allows the first construal in which the adjunct modifies the Reference Time.

(1) contains V2 root clauses with a periphrastic tense, i.e. the past perfect of vallen, 'fall'. (2) illustrates V2 root clauses with a simple tense, the simple past tense of the verb vallen, 'fall'. (2a) has the finite verb, viel, 'fell', in second position, preceded by the temporal clause. ( $2 b)$ departs from the V2 order in that the finite verb is preceded by two constituents: the adverbial clause and the subject. As before, $(2 b)$ is acceptable in WF and is unacceptable in StD. In contrast with (1a) and (1b), (2a) and (2b) do not differ in their temporal interpretation: in both, the temporal clause specifies the past Event Time. This is expected: the difference between Reference Time and Event Time is neutralised in the simple tenses because Reference Time and Event Time coincide (Reichenbach 1947). 
(2) a. Standard Dutch

Oan-k toekwamen, viel den eletriek uit. when I arrived fell the electricityout 'When I arrived, there was a power failure.'

\section{b. West Flemish}

Oan-k toekwamen, den eletriek viel uit. when I arrived the electricity fell out 'When I arrived, there was a power failure.'

This chapter addresses the interpretation of the non-inverted V3 patterns in (1b) and (2b), building on work with Ciro Greco (Haegeman \& Greco 2018a,b), which I summarize below. In the regular inverted V2 pattern the initial constituent is merged TP-internally and moved to the left periphery. The interpretive relation with the modal or temporal values of the associated clause are established through reconstruction. To account for the asymmetries in (1), I adopt Haegeman and Greco's hypothesis that in the V3 pattern the initial adverbial constituent is merged as an extra clausal constituent and that reconstruction is not available. For a main clause external constituent to be able to be interpreted as a modifier of TPinternal values, the tensed verb of the associated clause has to be moved to a high left peripheral head. In non-inverted V 3 patterns with the past perfect, only matrix RefT construal is available for an initial temporal adjunct. This restriction follows from the analysis combined with the assumption that RefT is encoded on a head that participates in the head chain created by the moved finite auxiliary, while EvT is encoded on a lower functional head which does not participate in the movement chain. In the simple past tense, the contrast between RefT and EvT readings is neutralised because the tensed lexical verb moves to the left periphery and, as a result, the head encoding EvT also participates in the chain created by the movement of the finite verb.

The chapter is organised as follows. Section 2 shows that in Standard Dutch, a speech act modifying adjunct can appear as the initial constituent in a linear V3 pattern both with non subject-initial V2 clauses and with subject-initial V2 root clauses. Section 3 shows that central adverbial adjuncts also combine with a regular $\mathrm{V} 2$ root clause, giving rise to a linear V3 pattern. In StD, this pattern is only licit provided the V2 root clause is non subject-initial and hence the analogues of (1b) and (2b), in which a central adverbial precedes a subject-initial V2 root clause, are not 
accepted. Section 4 develops a syntactic account for V3 configurations with initial adjuncts. In Section 5, this account is shown to capture the divergence in the temporal readings between the inverted and the noninverted patterns in the periphrastic tenses. Section 6 briefly discusses an alternative cartographic implementation of the syntax of V2, which allows the reconciliation of the asymmetric analysis of V2 with Schwartz and Vikner's (1996) hypothesis that 'the verb always leaves IP in V2 clauses. Section 7 is a summary.

\section{Speech act modifiers and FrameP}

\subsection{Speech act modifiers}

WF (1b) and (2b) constitute a V2 transgression (Catasso 2015). The very acceptability of these patterns is surprising; their unacceptability in StD seems to follow straightforwardly from the V2 constraint. However, as shown in a.o. Zwart (2005); Broekhuis \& Corver (2016) and Haegeman \& Greco $(2018 \mathrm{a}, \mathrm{b}), \mathrm{StD}$ does allow some V2 transgressions. V3 patterns featuring initial speech act modifiers are a case in point: in these, the adverbial adjunct in the V3 configuration is interpreted independently from the propositional content of the V2 clause. Speech act modifiers have been argued to be extra-cyclic (Zwart 2005); main clause external (Broekhuis \& Corver 2016; Haegeman \& Greco 2018a,b) or extra-sentential (AstrucAguilera 2005), i.e. they occupy a position outside the V2 root clause. (cf. Meinunger (2004) and Frey (2012)). In (3), a regular V2 clause is preceded by a speech act modifier, leading to a V3 linear order:

\section{(3) Standard Dutch}

$\begin{array}{llllll}\text { Als je het mij } & \text { vraagt, hij had geen kans. } \\ \text { if } & \text { you it } & \text { me ask he had no chance }\end{array}$

'If you ask me, he did not have a chance.'

The conditional clause in (3) frames the V2 clause as a whole, encoding a felicity condition for the utterance (cf. Astruc-Aguilera 2005; Scheffler 2008 and references cited). There is no temporal alignment between the adjunct and the V2 clause: the adjunct expresses a present time condition on the speech act, 'if you ask me now'; the proposition encoded in the V2 clause is situated in the past: 'he did not have a chance then'. In licit StD non-inverted V3 with an initial speech act modifier, the latter can thus plausibly be viewed as extra-sentential, it is not integrated in the matrix V2 clause. 


\subsection{Discourse structure beyond the narrow syntax}

The consensus in the literature is that (3) does not violate the V2 constraint because the speech act modifying adjunct is 'outside' the syntactic domain to which V2 applies. Building on Auer's (1996) intuition, Haegeman \& Greco $(2018 \mathrm{a}, \mathrm{b})$ postulate a discourse-building head Frame which combines a full-fledged V2 utterance, with a constituent that sets the relevant context for that utterance. As shown in (4), Haegeman \& Greco (2018a) label the V2 root clause ForceP, in line with the cartographic tradition (Rizzi 1997) and to signal that this layer encodes the illocutionary potential of the clause. ForceP essentially corresponds to $\mathrm{CP}$ or to the topmost layer in an articulated CP. Below I will mainly use the label CP, for convenience. But see section 6 for a brief cartographic reinterpretation.

Adj-XP, the constituent hosted by SpecFrameP, introduces an entity (or a set of entities) in the discourse in relation to which the proposition conveyed by the associated V2 root clause is interpreted as relevant. When Adj-XP is a speech act modifier, as in (3), the constituents of FrameP are construed independently: the denotation of Adj-XP does not impact on the truth conditions of the proposition encoded in ForceP.

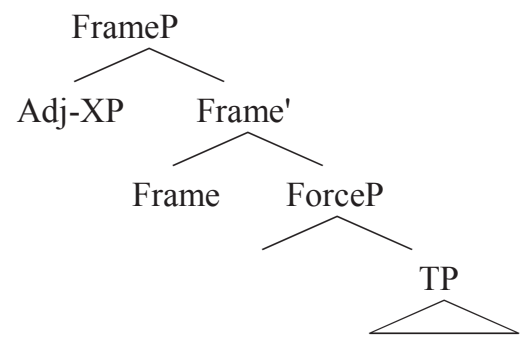

In (5a), the interpretation of Adj-XP, the speech act modifier als je het moet weten, 'if you must know', can be seen to be governed by a strict locality condition as schematized in (5b): Adj-XP encodes a condition on the matrix speech act; crucially, Adj-XP cannot modify the speech act embedded under zeggen, 'say'. Haegeman \& Greco (2018a,b) generalize this locality condition to cover the interpretation of all such Adj-XP. 
(5)

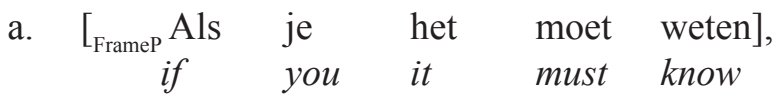

${ }_{\mathrm{CP}}[\mathrm{ze}]$ zei [da-ze het niet kon betalen] $]$. she said that-she it not could pay

'If you must know, she told me she couldn't pay for it.'

b. $\quad\left[_{\text {FrameP }} \operatorname{Adj}-\mathrm{XP}\left[{ }_{\text {Frame }}\right]\left[{ }_{\mathrm{CP}} \ldots\left[_{\mathrm{TP}} \ldots\right]\right]\right]$

\section{Central adverbial clauses}

Central adverbial adjuncts are semantically integrated into the main clauses which they modify, expressing, for instance, temporal or modal values of the associated proposition. Accordingly, one might expect that a central adverbial adjunct should be illicit as the specifier of FrameP, i.e. occurring as the initial adverbial constituent in V3 configurations. However, as shown in Haegeman \& Greco $(2018 \mathrm{a}, \mathrm{b})$, this prediction is incorrect. The relevant patterns are discussed in the present section.

\subsection{With inversion}

In both StD and WF, V3 configurations with central adjuncts in initial position are licit when the root $\mathrm{V} 2$ clause with which the adjunct combines itself displays subject-verb inversion. In (6a) the first constituent in the V2 root clause is a wh phrase, aan wie, 'to whom', while in (6b) it is a fronted object nominal MIJ, 'me'.

a. Als ik klaar ben met de handout, if I ready am with the handout aan wie moet ik hem (dan) tonen? to whom should I him (then) show

'When my handout is ready, to whom should I show it?'

b. Als er morgen een probleem is, if there tomorrow a problem is MIJ moet je niet bellen. me must you not call 'If there is a problem tomorrow, don't call me.' 
In (6), the initial adjunct restricts the temporal or modal values of the root clause. Some StD informants prefer to insert a resumptive adverbial dan in the matrix domain in (6a) as indicated by the parenthesized dan. Though of interest, I do not pursue this preference. (6) is evidence that central adverbial adjuncts can give rise to V3 linear order. Pursuing the proposal in Section 2, such adjuncts should be taken to occupy SpecFrameP and thus ought to be sentence-external. The availability of such patterns with central adverbials is thus paradoxical: assuming that the initial adjunct effectively occupies SpecFrameP, the question arises how it can be semantically integrated with the V2 clause to modify the temporal or modal coordinates of the proposition encoded. I address this point in Section 4.1.

\subsection{Without inversion}

While examples such as (6) are accepted by most speakers of Dutch (modulo, for some, dan-insertion in (6a)), there is a sharp contrast in the acceptability in relation to WF (1b) and (2b), whose StD analogues in (7) are unacceptable, regardless of dan-insertion. The unacceptability of (7) cannot simply be seen as a violation of the V2 constraint because (3), and (6) are evidence that linear V3 orders are licit in StD with speech act modifiers (3) and more importantly they are also licit with central (6) adjuncts.

a. *Toen ik aankwam, de elektriciteit was uitgevallen when I arrived the electricity was out.fallen 'When I arrived, there had been a power failure.'

b. *Toen ik aankwam, de elektriciteit viel uit. when I arrived, the electricity fell out

'When I arrived, there was a power failure.'

\section{SpecFrameP and the syntax of $\mathrm{V} 2$}

This section summarizes Haegeman \& Greco (2018a,b)'s account for the contrast between acceptable StD (3) and (6), and unacceptable StD (7).

\subsection{The inverted patterns}

Haegeman \& Greco (2018a,b)'s generalized locality condition on the interpretation of Adj-XP in SpecFrameP entails that the initial constituent in a V3 configuration can only modify the immediately adjacent matrix domain and cannot modify an embedded domain (cf. (5)). 
Following assumptions in the literature (a.o. Reichenbach (1947); Vikner (1986); Hornstein (1993); Cinque (1999); Demirdache \& Uribe Etxebarria (2004)), Haegeman \& Greco (2018a,b) assume that temporal and modal values of a proposition are encoded TP-internally. I present one implementation here, inspired by a.o. Zagona (1990); Stowell (1993); Demirdache \& Uribe-Extebarria (2004). In the schematic representation (8), CP is a shorthand for the left periphery, RefT is associated with the functional head $\mathrm{T}$, represented as $\mathrm{T}_{\mathrm{REF}}$, and EvT is associated with in a lower functional head, here represented provisionally as $\mathrm{V}_{\mathrm{EV}}$. Aspectual auxiliaries are taken to instantiate functional heads, labelled Aux (see Cinque 1999):

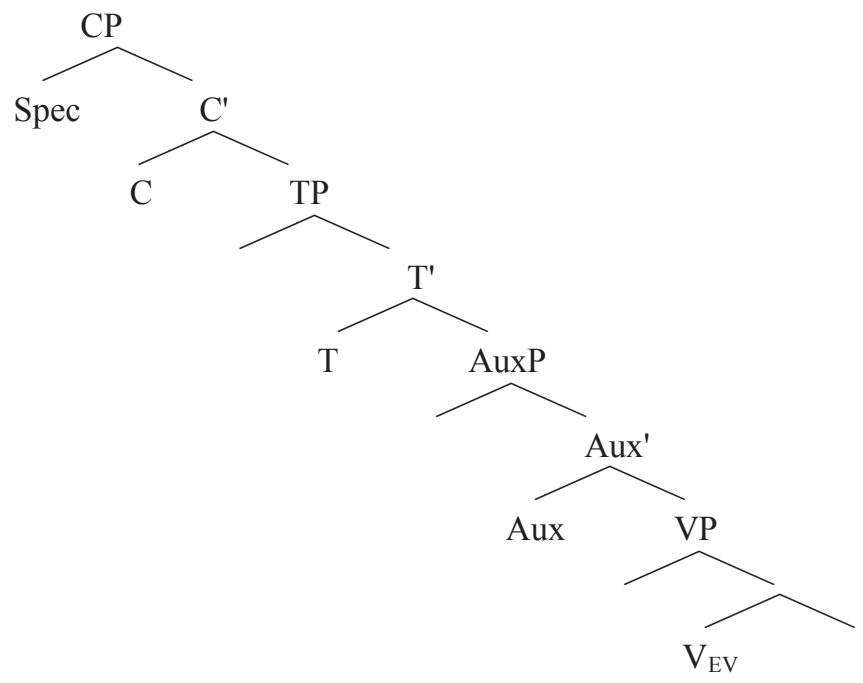

In $\mathrm{StD}$ (6a), the conditional clause als ik klaar ben met de handout, 'when my handout is ready', modifies the temporal domain of the matrix proposition. The intended construal is schematized by the dotted line in (9a). However, by Haegeman \& Greco's $(2018 \mathrm{a}, \mathrm{b})$ locality condition, the construal represented by the dotted line in (9a) should not be available because the adjunct $\mathrm{Adj}-\mathrm{XP}_{\mathrm{i}}$ does not have the required local relation with the matrix TP, from which it is separated by the left peripheral layer, CP. The configuration which would comply with the locality condition is represented by the continuous line in (9b), in which the initial adjunct is construed with the left periphery ('CP') of the V2 clause. Haegeman \& Greco (2018a,b) 
propose that in (6a), configuration (9b) is attained thanks to the movement of the finite verb moet ('must'). The idea is that head-movement of the finite verb creates a head chain, C-T, which 'indirectly' establishes the local connection between Adj-XP in SpecFrameP and the TP-internal temporal coordinate: the temporal features are brought up to $\mathrm{C}$ by $\mathrm{V}$-movement and then percolate to the $\mathrm{CP}$ layer, at which point they are directly related to the specifier of FrameP by virtue of the head Frame. In (9c), co-indexation between the initial adjunct and $\mathrm{CP}$ informally represents the modification relation.
a. $\left[_{\text {FrameP }}\right.$ Adj-X

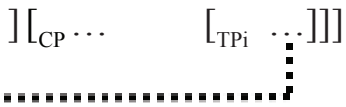
(StD)
b. $\left[_{\text {FrameP }} \operatorname{Adj}-\mathrm{XP}_{\mathrm{i}}\left[_{\text {Frame }}\right] \quad{ }_{\mathrm{CPi}}\right.$
$\left.\left.\left[{ }_{\mathrm{TP}} \cdots\right]\right]\right]$
c. $\left[_{\text {FrameP }}[\text { als ik klaar ben met de handout }]_{\mathrm{i}}\left[_{\text {Frame }}\right]\right.$ $\left[{ }_{\mathrm{CPi}}\right.$ [aan wie $]\left[\right.$ moet $\left.\left._{\mathrm{i}}\right]\left[_{\mathrm{TP}} \mathrm{ik} \ldots\left[_{\mathrm{Ti}} \mathrm{t}_{\text {moet }}\right]\left[\left[_{\mathrm{VP}} \ldots \mathrm{t}_{\text {aan wie }}\right]\right]\right]\right]$

\subsection{Standard Dutch subject-initial V2}

The contrast between StD inverted (6) and StD subject-initial V2 (7) suggests that the local relation attained through movement of the finite verb in (9c) is not attained in the non-inverted pattern (7). To capture the contrast, Haegeman \& Greco (2018a,b) adopt an asymmetric derivation of V2 (Travis 1984, Zwart 1997a,b). As a first approximation, inverted V2 in (6) is derived as in (10a), while non-inverted subject-initial V2 in (7) is derived as in (10b), where the subject remains in its canonical position (Spec,TP) and the finite verb occupies a TP-internal head.

$(\mathrm{StD} ; \mathrm{WF})$

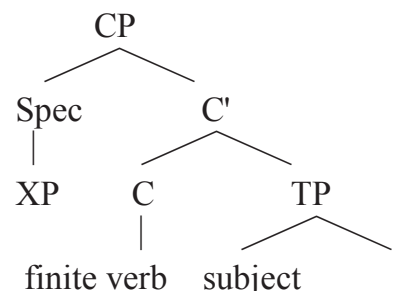




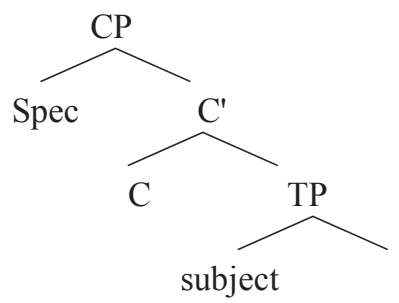

When a central adverbial Adj-XP combines with a non-inverted V2 clause, the locality relation between Adj-XP in SpecFrameP and the matrix temporal coordinate cannot be attained: in (10c), the adjunct toen ik aankwam ('when I arrived') cannot modify the components inside TP, from which it is separated by the CP layer:

$$
\text { c. } *\left[_{\text {FrameP }} A d j-\mathrm{XP}_{\mathrm{i}}\left[_{\text {Frame }}\right]\left[\left[_ { \mathrm { CP } } [ _ { \mathrm { C } } ] \left[_{\mathrm{TPi}} \text { subject }\left[_{\mathrm{T}} \text { finite verb }\right] \ldots\right.\right.\right.\right.
$$

\subsection{West Flemish subject-initial V3}

The WF analogues of StD (7), (1b) and (2b), are acceptable. Haegeman $\&$ Greco $(2018 a, b)$ ascribe the difference in the status of StD (7) and WF $(1 b, 2 b)$ to the derivation of subject-initial V2. Based on the argumentation above, we need to ensure that in ( $1 \mathrm{~b})$ and $(2 \mathrm{~b})$ the matrix temporal/modal coordinates are accessible to the initial adjunct in the V3 configuration: this will be achieved if WF subject-initial V2 patterns do implicate V movement to the $\mathrm{C}$ domain, as in (11):

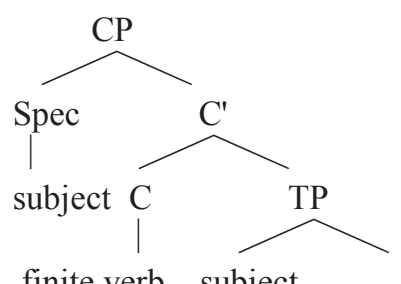

finite verb subject

In other words: the difference between WF (1b, 2b) and StD (7) is attributed to micro variation in the derivation of subject-initial V2. That subject- 
initial V2 may not be uniformly derived in all varieties of Dutch was first explored in Postma $(2011,2013) .^{2}$

In line with Travis (1984) and Zwart (1997a,b), Haegeman \& Greco $(2018 \mathrm{a}, \mathrm{b})$ cast the difference between the derivations of StD and WF subject-initial V2 in terms of whether the verb does or does not leave the TP domain. However, see Section 6 for a cartographic reinterpretation.

\section{The interpretation of the temporal adjunct in the WF subject- initial $V 3$ patterns}

\subsection{The problem}

Let us return to the contrast in the temporal interpretation of the initial adverbial clauses in WF (1) and (2), repeated in (12).

\section{West Flemish \\ a. Oan-k toekwamen was den eletriek utgevallen. when I arrived was the electricity out.fallen \\ (i) 'When I arrived, there had been a power failure.' \\ (ii) 'When I arrived, there was a power failure.'}

b. Oan-k toekwamen, den eletriek was utgevallen. when I arrived the electricity was out.fallen 'When I arrived, there had been a power failure.'

2 Ultimately, the proposed difference in the derivation of subject initial V2 should be tied in with other properties of these two varieties of Dutch. StD and WF also differ in relation to the syntax of existential expletives. In the canonical TP-internal subject position, i.e. the position to the immediate right of the complementizer in embedded clauses (ia) and in the post-verbal position in inverted V2 (ib), the expletive is (d)er ('there'). In non-inverted V2, the sentence-initial subject expletive is $t$ ('it') (ic). StD does not deploy a specialised expletive in initial position: er ('there') is used throughout. For reasons of space, I cannot dwell on this here.
(i) a. 'T Stonden
a
drie mensen.
it-stood
already
three people

'There were already three people.'
b. dan-der a drie mensen stonden that-3PL-there already three people stood

'that there were already three people

$\begin{array}{llll}\text { c. In de gang } & \text { stonden-der } & \text { drie } & \text { mensen. } \\ \text { in the corridor, } & \text { stood } \text { - there } & \text { already } & \text { three people }\end{array}$

'In the corridor, there were already three people.' 
c. Oan-k toekwamen, viel den eletriek uit. when I arrived fell the electricity out 'When I arrived, there was a power failure.'

d. Oan-k toekwamen, den eletriek viel uit. when I arrived the electricity fell out 'When I arrived, there was a power failure.'

With a periphrastic past perfect in the root V2 clause, the 'regular' V2 pattern (12a) and the V3 pattern (12b) differ in temporal construal. (12a) is ambiguous. In one reading, the initial adjunct oan-k toekwamen ('when I arrived') modifies the Reference Time; in a second reading, the adjunct modifies the Event Time. (12b) only retains the reading according to which the adverbial clause modifies the Reference Time. With a non-periphrastic simple past in the root V2 clause, the regular V2 pattern (12c) and the V3 pattern (12d) have the same construal: the adjunct clause modifies the Event Time.

\subsection{The constituent in SpecFrameP cannot be reconstructed}

\subsubsection{Embedded construal}

As shown in Haegeman \& Greco (2018a,b), in the regular V2 pattern an initial adjunct can be reconstructed to a clause-internal position, but the initial adjunct in a non-inverted V3 configuration cannot be so reconstructed. I provide one illustration from WF here. In the regular V2 pattern (13a), the initial adjunct modifies either the matrix Event Time, 'the claim was made when it was ready', or the embedded Event Time, 'she will make a call when it is ready'. In the non-inverted V3 pattern (13b), the latter construal is unavailable: the adjunct must modify the matrix Event Time. See the papers cited for more examples.

\section{(13) West Flemish}

a. Oa-t gereed was, zei ze da ze ging bellen. when-it ready was said she that she would call

b. Oa-t gereed was, ze zei da ze ging bellen. when-it ready was she said that she would call 
This contrast follows from Haegeman \& Greco's $(2018 \mathrm{a}, \mathrm{b})$ locality condition on the construal of SpecFrameP. For (13a), the initial adjunct originates either in the matrix domain or in the embedded domain. The embedded reading is attained by reconstruction. In (13b), the initial adjunct is main clause external (Spec,FrameP) and can only be construed with the local ForceP, in line with the earlier discussion.

\subsubsection{Temporal interpretation}

The contrast in interpretation between WF (12a) and (12b), repeated in (14a) and (14b), can be related to the locality condition on the interpretation of XP-Adj in SpecFrameP. In terms of a Reichenbach style interpretation, the initial adjunct oan- $k$ toekwamen, 'when I arrived', in (14a) either modifies the Reference time (RefT) or the Event Time (EvT); that in (14b) modifies RefT.
a. Oan-k toekwamen, was den eletriek utgevallen. when-I arrived was the electricity out fallen

(i) 'When I arrived, there had been a power failure.'

(ii) 'When I arrived, there was a power failure.'

b. Oan-k toekwamen, den eletriek was utgevallen. when-I arrived the electricity was outfallen 'When I arrived, there had been a power failure.'

(15) illustrates the two patterns with a simple past tense, in which RefT and EvT coincide (Reichenbach 1947). The contrast in (14) is no longer detected: both the regular V2 configuration (15a) and the non-inverted V3 configuration (15b) receive the construal according to which the initial adjunct is a temporal specification of the past event.

(15) a. Oan-k toekwamen, viel den eletriek uit. when I arrived fell the electricity out 'When I arrived, there was a power failure.'

b. Oan-k toekwamen den eletriek viel uit. when I arrived, the electricity fell out 'When I arrived, there was a power failure.' 
The asymmetry between periphrastic past perfect in (14) and simple past in (15) follows from the interaction between the adjunct oan-k toekwamen ('when I arrived') with the internal syntax of the V2 main clause, and in particular with the syntactic encoding of RefT on $\mathrm{T}_{\mathrm{REF}}$ and EVT on $\mathrm{V}_{\mathrm{EV}}$, as in (8) above. In the regular V2 pattern (14a, 15a), the initial adjunct is merged TP-internally (as a modifier of RefT or EvT) and moves to a specifier position in the left periphery. Reconstruction of the adjunct will ensure the appropriate construal (RefT; EvT). In the non-inverted V3 pattern, Adj-XP occupies SpecFrameP, i.e. it is external to CP. Following Haegeman \& Greco (2018a,b), Adj-XP can only be construed in a local relation with CP: this means that Adj-XP in SpecFrameP can only be related to the TPinternal temporal coordinates, RefT and EvT, via the head chain created by finite verb movement to $\mathrm{C}$. In the periphrastic tenses, the relevant head chain is created by the movement of the finite aspectual auxiliary. In the schematic representation (16), the auxiliary head-moves to $\mathrm{C}$ via the projection encoding RefT. The chain headed by the auxiliary in $\mathrm{C}$ contains the head T which encodes RefT, allowing construal of Adj-XP with RefT. EvT is encoded on a lower projection associated with the participle, which itself does not move to Force. Hence, the head chain created by the moved auxiliary does not connect up with EvT and EvT is inaccessible to Adj-XP.

\section{West Flemish}

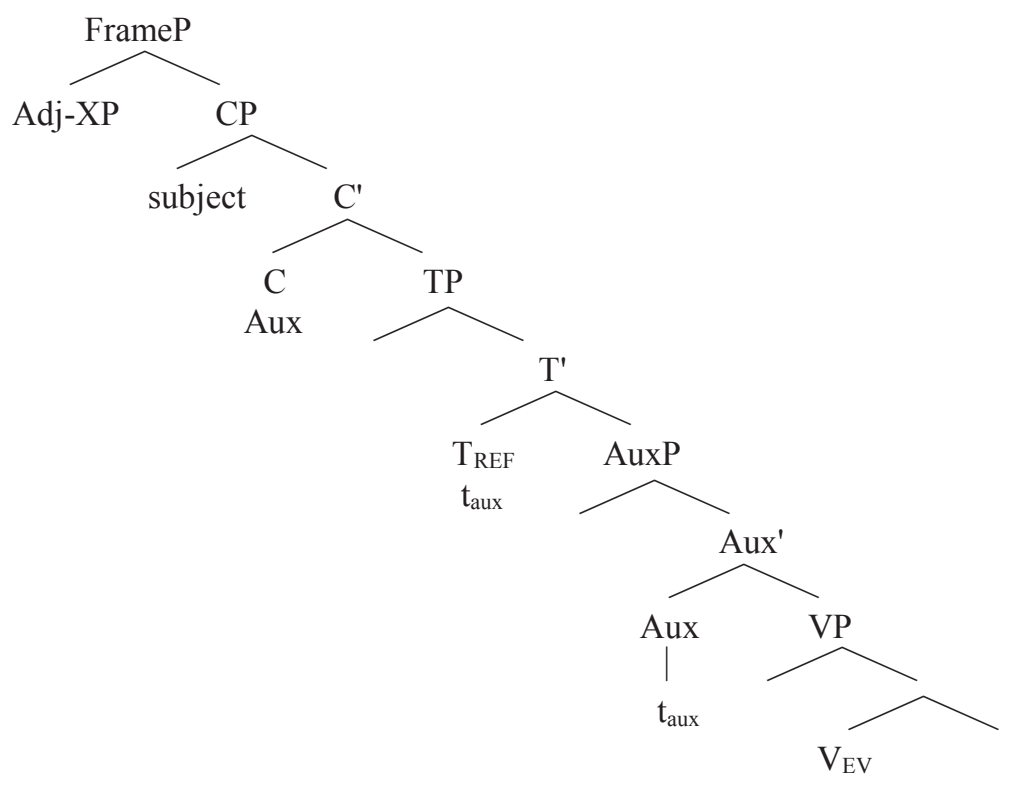


In simple tenses, the head chain is created by the moved lexical verb and thus implicates, $\mathrm{V}_{\mathrm{Ev}}$, which encodes EvT, hence Adj-XP can modify the EvT as in (17):

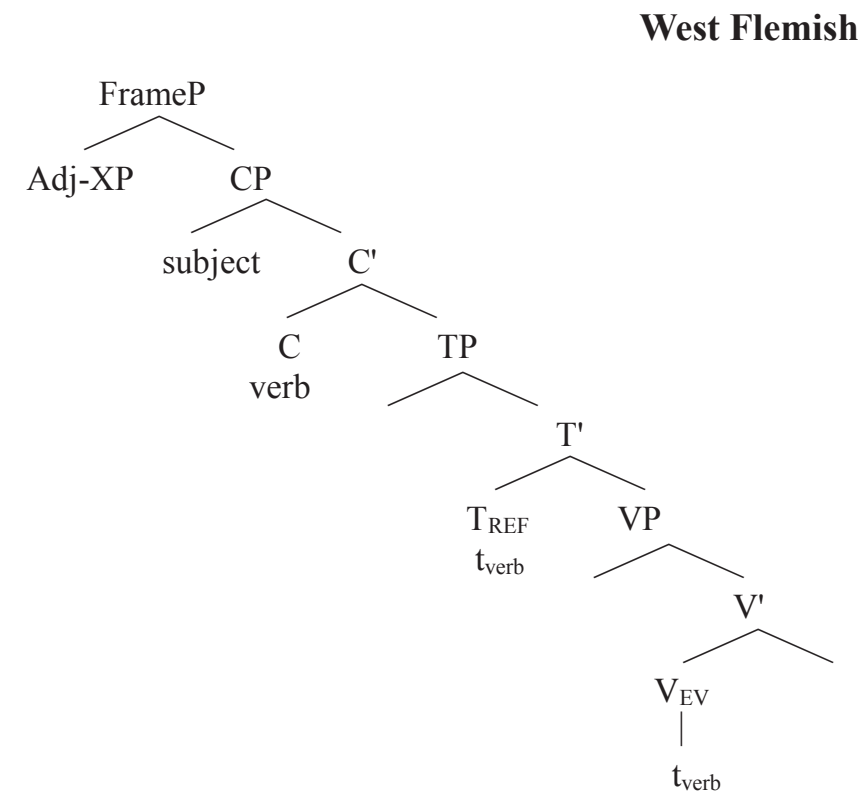

\section{The verb always leaves IP in V2 clauses: a cartographic rein- terpretation}

So far, I have been assuming the standard model of clause structure with TP dominated by $\mathrm{CP}$, leaving aside further articulations of the left periphery because these were not relevant for the argumentation. I have cast the difference between the derivations of StD and WF subject-initial V2 in terms of whether the verb does or does not leave the TP domain and lands in C, a proposal in line with Travis (1984) and Zwart (1997a,b).

However, representations such as (10b) for subject-initial V2 obviously conflict with the convincing arguments put forward in seminal work by Schwartz \&Vikner (1996) that "the verb always leaves IP in V2 clauses". Observe that with a full implementation of the articulated cartographic approach to the left periphery (Rizzi 1997), however, this conflict disappears and representations (10) and (11) can be reconciled with the spirit (if not the letter) of Schwartz \& Vikner's (1996) position, while retaining the 
findings on micro-variation in the derivation of subject-initial V2 explored in Postma $(2011,2013)$.

Let us adopt the articulated left periphery developed for V2 languages by Haegeman (1996), Poletto (2013) \& Wolfe (2015, 2016), as endorsed in Haegeman \& Greco (2018a). Core ingredients are the idea that the left periphery minimally encodes illocutionary force and finiteness, as represented by the two core left peripheral functional heads Force and Fin, which respectively constitute the top layer and the bottom layer of an articulated CP. Discourse-related functional layers such as FocP or TopP are sandwiched between ForceP and FinP. Following Wolfe (2016), I assume that in the Germanic languages under discussion the V2 syntax is played out in relation to Force and Fin.

Representations (10) and (11) above can then be recast as in (18a-c). (10a) for non subject-initial V2 patterns in all varieties of Dutch is replaced by (18a): the verb exits TP and moves to Force via Fin. The first constituent of the V2 pattern moves to SpecForceP via SpecFinP. (10b) for StD subject-initial V2 patterns is replaced by (18b). The contrast between (18a) and (18b) retains the asymmetry between non subject-initial V2 patterns and subject-initial V2 patterns in that the finite verb remains in a lower position in the latter; differently from Travis (1984) and Zwart (1997a,b), the asymmetry is played out at the level of the split CP. In $(18 \mathrm{a}, \mathrm{b})$, the finite verb does indeed "leave IP", to use Schwartz \& Vikner's wording (1996). WF subject-initial V2 is derived as in (18c), with the finite verb targeting Force.
a. $\left[_{\text {ForceP }} \mathrm{XP}\left[_{\text {Force }} \mathrm{V}\right.\right.$-fin $]$

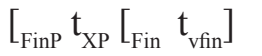
$\left[{ }_{T P}\right.$ subject... $\left.\left.\left.\mathrm{t}_{\mathrm{vfin}} \ldots\right]\right]\right]$
$(\mathrm{StD} ; \mathrm{WF})$
b. $\left[_{\text {ForceP }}\left[{ }_{\text {Force }}\right]\left[_{\text {FinP }}\right.\right.$ subject $\left[_{\text {Fin }}\right.$ V-fin $]$
$\left.\left.\left[{ }_{\mathrm{TP}} \ldots\right]\right]\right] \quad(\mathrm{StD})$
c. $\left[_{\text {ForceP }}\right.$ subject $\left[{ }_{\text {Force }} \mathrm{V}\right.$-fin $]\left[\left[_{\text {FinP }} \mathrm{t}_{\text {subject }}\left[\left[_{\text {Fin }} \mathrm{t}_{\text {vfin }}\right]\left[\left[_{\mathrm{TP}} \ldots \mathrm{t}_{\text {vfin }} \ldots\right]\right]\right]\right.\right.$

For the temporal interpretation of adjuncts in SpecFrameP, we would have to assume that the strictly local relation between SpecFrameP and ForceP plays the crucial role in creating the local relation between the initial adjunct and the temporal values generated in the TP domain and which are now available at the level of Fin. 


\section{Summary}

Inverted V3 patterns in which an initial adjunct precedes a V2 root clause with subject-verb inversion are licit in all varieties of Dutch, regardless of whether the adjunct modifies the speech act as a whole or the temporal or modal coordinates of the proposition encoded in the TP domain. The noninverted V3 pattern, in which an initial adjunct precedes a subject-initial V2 root clause, is restricted. In StD, the pattern is limited to those cases in which the initial adjunct belongs to the class of speech act modifiers. In WF, both speech act modifiers and central adverbial modifiers may constitute the first constituent in a non-inverted V3 pattern; in this pattern, central adjuncts are interpretively.

The starting hypothesis is that in a V3 pattern the initial constituent is main clause external and that its interpretation is regulated by Haegeman \& Greco's $(2018 \mathrm{a}, \mathrm{b})$ strict locality condition. Ceteris paribus, the initial constituent modifies the utterance, i.e. the associated V2 root clause as a whole. This construal corresponds to that available for speech act modifiers. Initial central adverbial clauses in V3 patterns can modify the temporal values of the associated root clause provided a local relation can be built between the central adjunct and the temporal coordinates of the root V2 clause. For Haegeman \& Greco (2018a,b), this local relation can be attained via the movement of the finite verb to the functional head $\mathrm{C} /$ Force, which has the appropriate local relation with the constituent in FrameP.

In non-inverted V3 patterns with the past perfect, only matrix RefT construal is available for an initial temporal adjunct. This restriction follows from the analysis combined with the assumption that RefT is encoded on a head that participates in the head chain created by the moved finite auxiliary, while EvT is encoded on a lower functional head which does not participate in the movement chain. In the simple past tense, the contrast between RefT and EvT readings is neutralised because the tensed lexical verb moves to the left periphery and, as a result, the head encoding EvT also participates in the chain created by the movement of the finite verb.

The chapter also shows how given a cartographic implementation of V2 Schwartz \& Vikner's (1996) hypothesis that the finite verb always leaves IP in V2 clauses can be reconciled with an asymmetric derivation of V2 as in Travis (1984). 


\section{References}

Astruc-Aguilera, Lluisa. 2005. The form and function of extra-sentential elements. Cambridge Occasional Papers in Linguistics 2. 1-25.

Auer, Peter. 1996. The pre-front field in spoken German and its relevance as a grammaticalization position. Pragmatics 6. 295-322.

Broekhuis, Hans \& Norbert Corver. 2016. Dutch syntax. Verbs and verb phrases. Volume 3. Amsterdam: Amsterdam University Press. doi:10.26530/ OAPEN 614910.

Catasso, Nicholas. 2015. On post initial aber and other syntactic transgressions: some considerations on the nature of V2 in German. Journal of Germanic Linguistics 27. 318-365,

Cinque, Guglielmo. 1999. Adverbs and functional heads. New York/Oxford: Oxford University Press.

Demirdache, Hamida \& Miriam Uribe-Etxebarria. 2004. The syntax of time adverbs. In Jacqueline Guéron \& Jacqueline Lecarme (eds.), The syntax of time, 143-190. Cambridge, MA: MIT Press.

Frey, Werner. 2012. Peripheral adverbial clauses, their licensing and the prefield in German. In Eva Breindl, Gisella Ferraresi \& Anna Volodina (eds.), Satzverknüpfung - Zur Interaktion von Form, Bedeutung und Diskursfunktion, 41-77. Berlin: de Gruyter.

Haegeman, Liliane. 1996. Verb second, the split CP and null subjects in early Dutch finite clauses. GenGenP. Available on: http://ling.auf.net/lingBuzz/001059.

Haegeman, Liliane. 2003. Conditional clauses: external and internal syntax. Mind and Language 19. 318-339.

Haegeman, Liliane \& Ciro Greco. 2018a. West Flemish V3 and the interaction of syntax and discourse. The Journal of Comparative Germanic Linguistics 21. 1-56. doi:10.1111/1468-0017.00230.

Haegeman, Liliane \& Greco, Ciro. 2018b. Main clause external constituents and the derivation of subject-initial verb Second. Nederlandse Taalkunde, 23. 2355. doi: 10.5117/NEDTAA2018.1.HAEG

Hornstein, Norbert. 1993. As time goes by: Tense and universal grammar. Cambridge, Mass.: MIT Press.

Meinunger, André. 2004. Verb position, verbal mood and the anchoring (potential) of sentences. In Horst Lohnstein \& Susanne Trissler (eds.), The syntax and semantics of the left periphery, 313-341. Berlin: Mouton de Gruyter.

Poletto, Cecilia. 2013. On V2 types. In Claudia Parodi \& Sylvia Luraghi (eds.), The Bloomsbury companion to syntax, 154-174. Bloomsbury: London.

Postma, Gertjan. 2011. Het verval van het pronomen $d u$ in het Middelnederlands. Dialectgeografie en historische syntaxis. Nederlandse Taalkunde 17. 56-87. 
Postma, Gertjan. 2013. Clause-typing by [2] - The loss of the 2nd person pronoun $d u$ 'you' in Dutch, Frisian and Limburgian dialects. In Victoria CamachoTaboada, Angel Jiménez-Fernandez, Javier Martin-Gonzales \& Mariano ReyesTejedor (eds.), Information structure and agreement, 218-254. Amsterdam: Benjamins.

Reichenbach, Hans. 1947. Symbolic logic. Berkeley: University of California.

Rizzi, Luigi. 1997. The fine structure of the left periphery. In Liliane Haegeman (ed.), Elements of grammar, 281-337. Dordrecht: Kluwer. doi:10.1007/978-94011-5420-8_7.

Schwartz, Bonnie \& Sten Vikner. 1996. The verb always leaves IP in V2 clauses. In Adriana Belletti \& Luigi Rizzi (eds.), Parameters and functional heads. Oxford: Oxford University Press, 11-62. Reprinted in Ian Roberts (ed.) (2007). Comparative grammar-Critical concepts, vol. 5, 244-302. Routledge, London.

Scheffler, Tajana. 2008. Relevance conditionals as utterance modifying adverbials. In Olivier Bonami \& Patricia Cabredo Hofherr (eds.), Empirical issues in syntax and semantics 7, CNRS: Colloque de syntaxe et de sémantique à Paris, 373-392. http://www.cssp.cnrs.fr/eiss7/.

Travis, Lisa. 1984. Parameters and effects of word order variation. Cambridge, MA Mass: MIT dissertation.

Vikner, Sten. 1985. Reichenbach revisited: one, two, or three temporal Relations? Acta linguistica hafniensia 18. 81-9.

Wolfe, Sam. 2015. The nature of Old Spanish Verb Second reconsidered. Lingua 174. 132-155. doi:10.1016/j.lingua.2015.06.007.

Wolfe, Sam. 2016. On the left periphery of V2 languages. Rivista di Grammatica Generativa: Selected papers from the 41st Incontro di Grammatica Generativa. 287-310.

Zwart, C. Jan-Wouter. 1997a. The Germanic SOV languages and the universal base hypothesis. In Liliane Haegeman (ed.), The new comparative syntax. 246264. London: Addison-Wesley.

Zwart, C. Jan-Wouter 1997b. Morphosyntax of verb movement: A minimalist approach to the syntax of Dutch. Dordrecht: Kluwer.

Zwart, Jan-Wouter. 2005. Verb second as a function of merge. In Marcel den Dikken \& Cristina M Tortora (eds.), The function of function words and functional categories, 11-40. Amsterdam: John Benjamins. doi:10.1075/la.78.03zwa. 